\title{
Hemangioma of the Umbilical Cord: Report of a Case
}

\author{
Adele Caldarella ${ }^{1}$, Anna Maria Buccoliero' ${ }^{1}$, Antonio Taddei², \\ Luciano Savino ${ }^{3}$, Gian Luigi Taddei ${ }^{1}$ \\ ${ }^{1}$ Dipartimento di Patologia Umana e Oncologia-Università degli Studi di Firenze, \\ Firenze, Italy \\ ${ }^{2}$ Dipartimento di Area Critica Medico - Chirurgica - Sezione Chirurgia Generale e DC, \\ Firenze, Italy \\ ${ }^{3}$ Dipartimento di Ginecologia, Perinatologia e Medicina della Riproduzione, \\ Firenze, Italy
}

\section{Summary}

A 31-year-old woman with a large placental tumor underwent a caesarean section. After delivery, the lesion, detected by ultrasound examination, was found to originate from the umbilical cord. A live female infant with cyanosis, hypotonia and diffuse edema was delivered. A review of the literature, which revealed 31 cases of umbilical cord hemangioma, showed that this tumor has a polymorphous presentation. Some fetuses and infants died from various causes, indicating that a close followup is necessary in these pregnancies

Key words: Hemangioma - Umbilical cord tumors

\section{Introduction}

Tumors of the umbilical cord are uncommon findings that can be discovered prenatally by ultrasound scanning [5]. Only two true tumors occur in the umbilical cord: angiomas and, more rarely, teratomas.

Although cord hemangioma is very similar to the more common placental hemangioma as regards origin and nature, the clinical significance of cord hemangioma is less well defined than placental hemangioma. Some authors speculate that large hemangioma of the cord may have the same clinical potential for adverse effects as that of similar size in the placenta [8].
The frequency of the funicular lesion is much lower than that of placental hemangioma: only 31 cases of cord hemangioma have been found in the literature, while several hundred cases of placental hemangioma have already been described [10].

\section{Case Report}

A 31-year-old woman, gravida 2, para 1, at 32 weeks of gestation, was referred to the Gynecologic Clinic for fetal distress. Ultrasound scan had revealed a large mass behind the placenta: there was no demonstrable link to the fetus or umbilical cord. The tumor displayed small echo-free areas of a supposedly vascular nature and, therefore, it was thought to be a chorangioma (Fig. 1).

The fetus showed hydrops fetalis and cardiomegalia. Umbilical flussimetria revealed that diastolic umbilical flow was absent, and fetal hypoxia was detected by cardiotocography.

A primary caesarean section was performed, and a female infant $(2,150 \mathrm{~g})$ with Apgar scores of 3 and 7 at both 1 and 5 minutes was delivered. The infant showed cyanosis, hypotonia and diffuse edema; the abdomen

Address for correspondence: Gian Luigi Taddei, Dipartimento di Patologia Umana e Oncologia, Università degli Studi di Firenze, viale Gian Battista Morgagni, 85, c.a.p. 50134, Firenze, Italy.

Phone: +39+055-413756, Fax: +39+055-4379868

E-mail: gl.taddei@unifi.it 
was globose, and an ascites was present. Ultrasound examination showed a right ventricular and atrial dilatation, with an increase in cardiac volume and compliance. Increased periphericol resistance was detected. Moreover, a pulmonary edema was documented.

There were no other clinical findings than umbilical tumor, displaying the fetal hydrops with ascites as well as cyanosis and hypoxia.

The infant recovered in a neonatal therapy care unit, and was treated medically. She improved rapidly, and after one month, she was discharged from hospital in stable conditions. At present, after 14 months, the infant is in good health.

The placenta weighed $650 \mathrm{~g}$ and measured $15 \times 12 \times$ $2.5 \mathrm{~cm}$. The umbilical cord segment measured $25 \mathrm{~cm}$ in length and ranged between 1.5 and $2.5 \mathrm{~cm}$ in diameter; it showed a large mass near to its placental end, weighing $600 \mathrm{~g}$ and measuring $13 \times 12 \times 7 \mathrm{~cm}$ (Fig. 2). The sur-

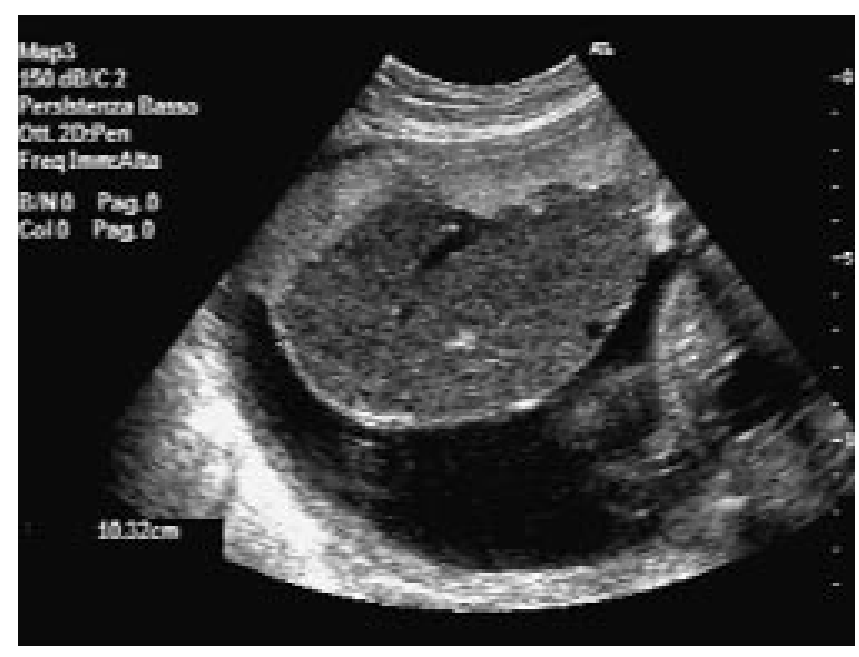

Fig. 1. Ultrasound scan showed a large mass behind the placenta, with echo-free areas of a probably vascular nature.

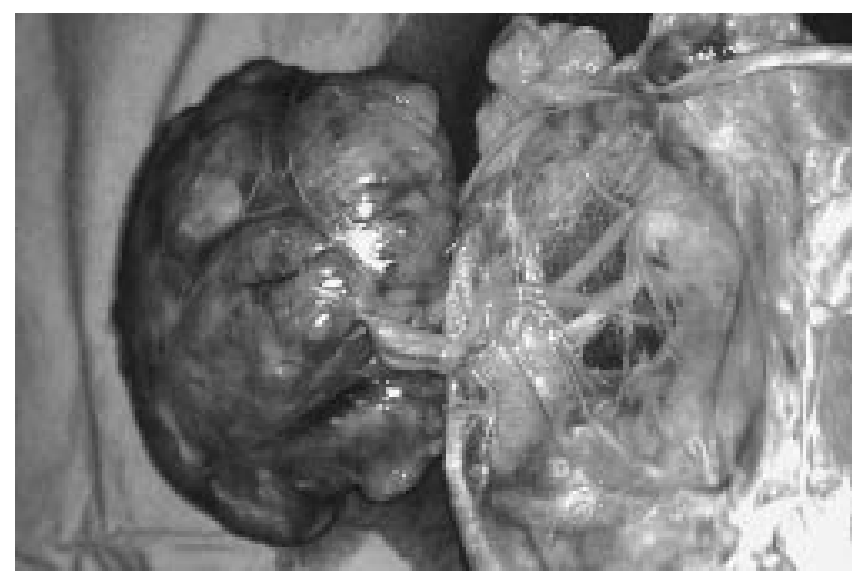

Fig. 2. Macroscopic examination revealed a large ovoid mass near the placental end. face was smooth and pale, with hemorrhagic areas and gelatinous appearance. A $3 \mathrm{~cm}$ long segment of normal cord was present between the lesion and the placental cord insertion.

The cut surface of the lesion revealed a translucent tissue with numerous vascular channels of varying size. The original three umbilical vessels could still be recognized within the tumor. There was no evidence of neoplastic tissue in the placenta. The diagnosis of umbilical cord hemangioma was made.

Histologically, the hemangioma was composed of a rich proliferation of capillary vessels disseminated in a myxoid stroma; the latter often seemed to be widely present, being hemangioma partially mixomatous in nature. Fibrin thrombi were present in some vascular structures; there was neither necrosis nor degeneration; neither inflammation nor osseous metaplasia was present. Cytologic features suggesting malignancy were absent; the proliferation index, as determined by analysis with Ki67 antigen (Dako, Glostrup, Denmark), was very low.

Immunohistochemical examination revealed the endothelial component of the channels: CD31 and CD34 (Dako, Glostrup, Denmark; Biogenex, San Ramon, California) delimited the thin wall, confirming the vascular nature of the lesion (Fig. 3)

Placenta examination revealed a small intraplacental hematoma and the presence of edematous villous stroma; scattered leukocytes were present in fetal membranes.

\section{Discussion}

The umbilical cord hemangioma consists of an angiomatous nodule, its size ranging from 0.2 to $18 \mathrm{~cm}$, generally encompassed by edema and myxomatous degeneration of Wharton's jelly, which is often cystic; [10, 15]. The edema is due to high permeability of angiomatous vessels that are placed in a soft, gelatinous tissue $[2,3,7]$. The hemangioma tends to be located at the placental end of the cord, and the associated cord swelling tends to develop a considerable distance toward the fetus $[3,9,10]$; an association with a hematoma is rare.

The nodule tends to be sharply demarcated from the surrounding stroma, often presenting a pushing border. It is composed of anastomosing vascular structures, delineated by endothelium. It may appear as either a capillary or cavernous hemangioma. However, as in our case, the microscopic features are often distorted by the stroma in which the tumor is set. The vascular channels may be widely dilated, and a variable amount of smooth muscle is always present. Fibrin thrombi may be present and associated with endothelial necrosis and degeneration or calcification and acute inflammation. Sometimes, stromal calcification or osseous metaplasia may occur [10]. 

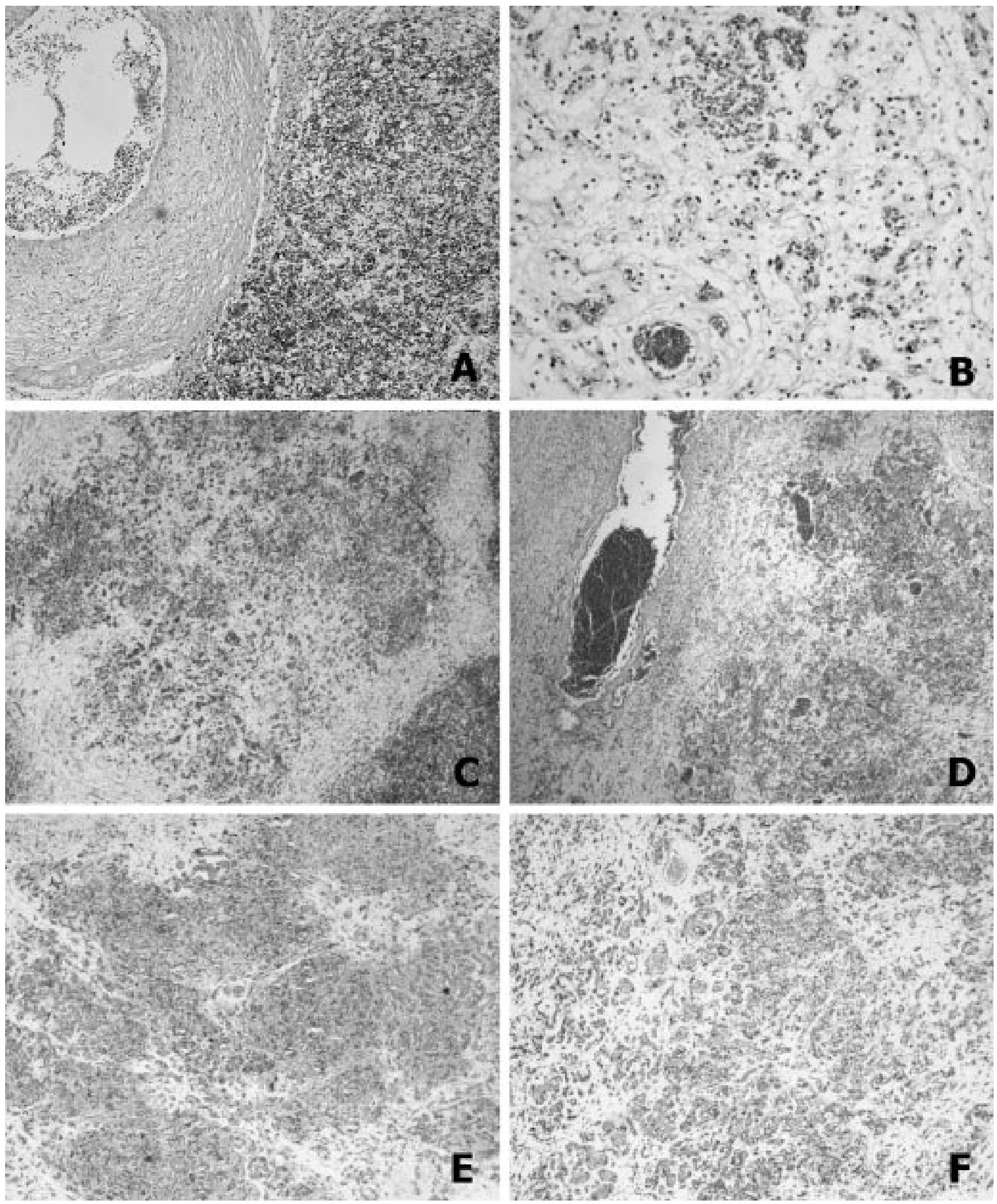

Fig. 3. A: Histologic section of the umbilical cord hemangioma apparently arising from umbilical vein $(\mathrm{H} \& \mathrm{E}, \times 25)$. B-F: Hemangioma nodule showing proliferation of capillaries; CD31 and CD34 positivity $(\mathrm{E}, \mathrm{F})$ in a myxoid stroma $(\mathrm{H} \& \mathrm{E}, \times 25)$. 
The tumor arises from one or more umbilical vessels, usually originating from the umbilical artery, less commonly from vein or both. If the tumor is located at the fetal end of the cord and is separated from the major umbilical vessels, it may arise from vitelline capillaries $[9,10]$. The vessels can also be derived from the primitive angiogenic mesenchyme of the developing cord [6]. A review done by Heifetz [10] revealed that of 11 cases of umbilical cord hemangioma, the tumor originated from one umbilical artery in five cases, from both an umbilical artery and vein in three cases, from all three main vessels in one case, from vitelline capillaries in one case, and from the umbilical vein in one case. In our case, the tumor was near the umbilical vein, presumably originating from this vessel.

Hemangioma should be considered in the differential diagnosis of tumoral lesions of umbilical cord; among these, cystic and solid lesions should be differentiated. The cysts generally derive from embryonic remnants of the umbilical cord; the origin of pseudocysts is due to myxoid degeneration of Wharton's jelly. The solid tumors are represented by teratomas and hemangiomas: teratomas are extremely rare and appear to be identical to placental teratomas. The umbilical cord hemangiomas must be differentiated from cord hematomas that generally appear as perivascular lakes of extravasated erythrocytes; sometimes, they can appear as angiomas: in this case, the lack of an endothelial component allows the diagnosis of hematoma [10].

The edematous imbibition of Wharton's jelly, with myxoid appearance, has led some authors to call this lesion "angiomyxoma"; a wide variety of diagnostic terms have been used in the literature to define this tumor as, for instance, hemangiofibromyxoma if a dense fibrous stroma was present, or myxangioma, underlining the myxomatous appearance, or cavernous hemangioma. All the reported cases had some features in common, and the morphology of umbilical cord hemangioma tended to be substantially uniform. Some authors, after having reviewed the literature, defined anatomopathologic criteria for the diagnosis of hemangioma: it is a vascular proliferation, with identifiable endothelial part, placed on the free segment of the umbilical cord, distinct from placental and fetal insertion [10].

The etiology and clinical significance of umbilical cord hemangiomas remain unclear. There is no association between maternal age, race, or gravidity and hemangioma development, nor exists a preponderance for a certain gender. Some authors consider these tumors as hamartomas, because they are present at birth, never develop metastasis, and are characterized by an abnormal mixture of tissues indigenous to the part with a predominance of one or more of these tissues. The lack of circumscription or encapsulation of these lesions and their intimate association, in some cases, with remnants of the omphalomesenteric system and umbilical vessels seem to support their interpretation as hamartomatous malformation [15].

The most frequent presentation is that of isolated fetal anomaly without other fetal malformations [12], although two cases of hemangioma with malformations have been described in the literature: one child died from heart malformations ten hours after birth, the other was a stillborn anencephalic fetus [16]. In other children, a severe physical and mental retardation, a nonimmune hydrops fetalis, a hydrocephalus with germinal matrix bleed, and necrotizing enterocolitis with later normalization were detected $[15,16]$.

Umbilical cord hemangioma is rarely associated with maternal hydramnios $[1,13]$, which is probably due to the fact that the cord surface amnion is less permeable than placental or membranous amnion and the transudate fluid remains entrapped within Wharton's jelly [11]. Increased alpha-fetoprotein levels are present in some cases; usually, there is a slight increase, but very high levels can sometimes be attained [8]. In our case, there was no change of this marker. As this tumor is rare, the diagnostic significance of alpha-fetoprotein is still unclear.

Twenty-eight cases of hemangioma of the umbilical cord have been examined: 11 were identified by prenatal ultrasonography, and 17 postnatally. Of the children having received a prenatal diagnosis, three died, from intrauterine death, polyhydramnios and multiple developmental anomalies, and hemorrhage after ultrasoundguided biopsy. Of the children in whom the tumor was detected postnatally, seven were stillborn $[9,12]$, underlying the importance of antenatal detection in these tumors. The high perinatal mortality and morbidity rate reported in association with this tumor is generally due to premature delivery, cardiac failure and nonimmune hydrops fetalis, severe fetal hemorrhage, intrauterine growth retardation, and intrauterine death $[6,10,12$, $15,16]$.

The causes of intrauterine fetal death have not been well established: some authors hypothesize that fetal demise might be due to the mechanical compression of the umbilical circulation by tumors $[9,10]$. Others described umbilical cord torsion as a possible cause of fetal death $[13,16]$. Recently, it was postulated that a stenosis of umbilical vessels caused by intravascular proliferation of the hemangioma might have led to reduced umbilical circulation. This reduction in the umbilical blood flow, already impaired by tumor compression, may cause fetal demise [9].

Thus, to avoid the intrauterine and postnatal complications, an early diagnosis of umbilical cord hemangioma is necessary. We recommend a close follow-up by ultrasound examination and, in some cases, color Doppler to elucidate the nature of placental masses as soon as possible. 


\section{References}

1. Armes JE, Billson VR (1994) Umbilical cord hemangioma associated with polyhydramnios, congenital abnormalities and perinatal death in a twin pregnancy. Pathology 26: $218-220$

2. Baylis MS, Jones RY, Hughes M (1984) Angiomyxoma of the umbilical cord detected antenatally by ultrasound. J Obstet Gynecol 4: 243-244

3. Benirschke K, Kaufmann P (2000) Pathology of the human placenta. 4th ed, pp 947. Springer-Verlag, New York

4. Carles D, Maugey-Laulom B, Roux D, Jimenez M, Saudubray F, Albert EM (1994) Anasarque foeto-placentaire létale secondaire à un hémangiome du cordon ombilical. Ann Pathol 14: 244-247

5. Clausen I, Thomsen SG (1992) Pseudotumors of the umbilical cord and fetal membranes. Acta Obstet Gynecol Scand 71: 148-150

6. Dombrowski MP, Budev H, Wolfe HM, Sokol RJ, Perrin E (1987) Fetal haemorrhage from umbilical cord hemangioma. Obstet Gynecol 70: 439-442

7. Fortune DW, Ostor AG (1980) Angiomyxomas of the umbilical cord. Obstet, Gynecol 55: 375-378

8. Fox H (1997) Pathology of the placenta. pp 488. W.B. Saunders Company, Philadelphia
9. Kamitomo M, Sueyoshi K, Matsukita S, Matsuda Y, Hatae M, Ikenoue T (1999) Hemangioma of the umbilical cord: stenotic change of the umbilical vessels. Fetal Diagn Ther 14: $328-331$

10. Heifetz SA, Rueda-Pedraza ME (1983) Hemangiomas of the umbilical cord. Pediatric Pathology 1: 385-398

11. Lewis SH, Perrin E (1999) Pathology of the placenta. 2nd ed, pp 411. Churchill Livingstone, Philadelphia

12. Miller KA, Gauderer MWL (1997) Hemangioma of the umbilical cord mimicking an omphalocele. J Pediatr Surg 32: 810-816

13. Mishriki YY, Vanyshelbaum Y, Epstein H, Blanc W (1987) Hemangioma of the umbilical cord. Pediatr Pathol 7: 43-49

14. Resta RG, Luthy DA, Mathony BS (1988) Umbilical cord hemangioma associated with extremely high alpha-fetoprotein levels. Obstet Gynecol 72: 488-491

15. Seifer DB, Ferguson JE, Behrens CM, Zemel S, Stevenson DK, Ross JC (1985) Nonimmune hydrops fetalis in association with hemangioma of the umbilical cord. Obstet Gynecol 66: 283-286

16. Sondergaard G (1994) Hemangioma of the umbilical cord. Acta Obstet Gynecol Scand 73: 434-436

Received: October 9, 2002

Accepted: January 8, 2003 